\title{
DISCURSO DE SAUDAÇÃO AO PROFESSOR CELSO LAFER, POR OCASIÃO DE SUA POSSE COMO TITULAR DO DEPARTAMENTO DE FILOSOFIA E TEORIA GERAL DO DIREITO
}

\begin{abstract}
SPEECH OF GRIETING OF THE PROFESSOR CELSO LAFER, FOR OCCASION OF THE OWNERSHIP
\end{abstract} OF THE TITLE OF FULL PROFESSOR FOR PHILOSOPHY OF I.AW

Tercio Sampaio Ferraz

Ao leitor

A publicação deste discurso, até hoje inédito, com o qual Celso Lafer foi por mim saudado por ocasião de sua posse como professor titular da Faculdade, é uma homenagem que se presta a ele por sua eleição para a Acadernia Brasileira de Letras, neste ano de 2006, como sucessor do mestre Miguel Reale. O discurso foi pronunciado no dia 07 de agosto de 1989. E, para os que acompanham sua trajetória de docente e homem público, poderá ser lido como o testemunho justo e profético, do amigo que o admira tanto.

Tercio Sampaio Ferraz Junior

Prezado Celso Lafer,

Incumbe-me a Congregação desta Faculdade de uma tarefa simples na sua obviedade e na sua ligação às tradições mais festivas desta Casa: saudá-lo, por sua nomeação para professor titular do Departamento de Filosofia e Teoria Geral do Direito. Tarefa, no entanto, que me sabe, neste momento, dificil e complexa, mas, sobretudo, prenhe de um sentimento pessoal que me confunde e me inibe. Sim, porque coube a mim a tarefa, a mim seu amigo de há mais de 29 anos, falar em nome de todos. Escolha muito justa e apropriada, pensarão muitos. Dramática no fundo e na forma, direi eu, no entanto.

Aristóteles. depois de exaltar a amizade como aquilo que há de mais necessário para viver, porque sem amigos ninguém quereria viver ainda que tivesse todos os outros bens, observa não sem certa cautela que quando os homens são amigos não há mais necessidade de Justiça, ao passo que se eles se contentam de ser justos, eles têm necessidade da amizade. Ao saudá-lo em nome da Congregação da Faculdade, incita-me o desejo de ser justo, de tecer o louvor certo àquele que merece a nossa

Professor Titular do Departamento de Filosofia e Teoria Giral do Direito da Faculdade de Direito da Universidade de São Paulo. Membro do Conselho Editorial da Revista da Faculdade de Direito da Universidade de São Paulo. 
amizade. Ao falar em nome dos colegas, inspira-me a justa homenagem de dizer publicamente aquilo que todos reconhecemos no traço harmonioso de uma carreira acadêmica. F, no entanto, em sendo seu amigo. antes, antes de tudo e acima de tudo, falece-me esta compulsão para o elogio equilibrado e justo, e em seu lugar brilha a evidência do redundante: ('elso Lafer, ora Celso Lafer é Celso Lafer, aquele companheiro de há 29 anos, cuja amizade cala as minhas palavras de um envolvente sentimento.

Por isso, meu caro amigo. estas palavras que lhe dirijo agora, em nome da Congregação, serão como olhos, turvos de lágrimas alegres, que tentam ver, não obstante, na figura do amigo, o exemplo acadêmico, o paradigma do intelectual, da dignidade do mestre, da lealdade do colega.

Saudamos Celso Lafer. Quem saudamos? Só podemos saber quem um homem é, diz-nos Hannah Arendt, se conhecemos a história da qual ele é o herói. O herói revelado pela sua história não precisa ter qualidades heróicas no sentido usual do termo. Embora a palavra conote imediatamente o afrontamento e a disposição de arcar com as conseqüências, o herói de sua história é, apenas, antes de mais nada, aquele que abandona o seu abrigo recôndito para mostrar quem é, para revelar e exibir sua individualidade. Um herói não é um semi-deus, é uma distinção que está ao alcance de qualquer homem livre. Mas esta coragem inicial que nos faz públicos, que abre o espaço da comunidade, é um traço significativo.

Herói de sua própria história, Celso Lafer é antes de mais nada alguém que cresceu no abrigo recôndito de sua circunstância familiar. Qual é, porém, esta circunstância? Formado num ambiente cultural cuja expressividade maior estava numa ética do trabalho e numa vocação prática, como ele próprio afirma de seu tio. Horácio Lafer, na Introdução que escreveu ao seu Perfil Parlamentar, ${ }^{1}$ Celso viu-se desde cedo, porém, inserido numa espécie de tensão intelectual gerada, de um lado, pela tradição judaica consubstanciada na Ética dos Pais, em que não a teoria, mas a prática era o principal, e, de outro, pelo fascínio que sobre ele exercia a tradição grega que realça a importância do ócio para a contemplação. Desta tensão nasceu-lhe desde logo o gosto pela política, que se traduzia para ele na conexão entre o pensar e a intersubjetividade da vida pública e social. exercitada desde cedo no âmbito menor da comunidade acadêmica. mas com uma projeção ampla, de espectro nacional, como acontecia, na Faculdade, nos anos que antecederam a Revolução de 1964.

Lembro-me particularmente de um dia, no ano de 1962. Expunha-nos, em aula, o Prof. Cesarino Júnior, princípios e fundamentos da legislação social. O assunto, 
para uma mocidade que via agitar-se o País entre as pendências ideológicas que iriam preparar 1964, provocava debates e tomadas de posição. Nomes, como o de Celso Furtado, suscitavam tensas discussões voltadas para a economia política nacional, em que a questão do desenvolvimento e do subdesenvolvimento ganhavam enorme significado. Solicitando a palavra, Celso Lafer com precisão e conhecimento, para surpresa do mestre Cesarino, desfiou em poucos minutos uma pertinente apreciação crítica da obra de Celso Furtado, a quem contrapunha as análises lúcidas de Hélio Jaguaribe. Revelava-se, para mim e para seus colegas, pela primeira vez, um traço marcante de sua personalidade intelectual: o exercício da capacidade de julgar, de uma faculdade de ver as coisas não apenas do próprio ponto de vista, mas na perspectiva de todos aqueles por ventura presentes, ou mesmo ausentes, compondo um auditório dotado de razoabilidade.

Essa Faculdade, conhecida como discernimento, grega na sua origem, e que os romanos tão bem exercitaram na forma da prudência, é, a meu ver, o modo como Celso Lafer enfrentou a tensão entre a tradição judaica da prática e o fascínio grego pela teoria. Há em sua maneira de ser essa elegância disciplinada do julgador. que persuade na esperança de eventualmente chegar a um acordo. Não é um especialista fechado na excentricidade tirânica de uma verdade solipsista e coactora. mas alguém, que em tudo o que fala e escreve, revela sempre algo de si mesmo. Esta revelação, para quem o conhece e com ele convive, deixa transparecer um senso de humanismo muito próprio, em que o valor humano e a eminência pessoal, juntamente com a amizade, jamais se sacrificam à primazia de uma verdade absoluta. Trata-se de um modo de ser ousado, ultrajantemente ousado até, sobretudo por referir-se à verdade. Mas o que de fato isto significa é que Celso Lafer está entre os autênticos humanistas. entre aqueles que são livres sob todos os aspectos, que exercem sua faculdade de julgamento para além de qualquer coerção que nos impõe a especialidade.

Daí também esta erudição fantástica que vem acumulando no correr dos anos, e que o fez debruçar sobre o direito e a política, sobre a filosofia e a literatura, com a postura do homem culto, aquele que sabe escolher sua companhia entre os sábios e os simples, entre coisas e pensamentos, em todo tempo e em toda parte.

Celso Lafer desde cedo escolhia suas companhias. Como que antevendo as lições que iria aprender de sua grande mestra Hannah Arendt, intuiu logo que o sentido da vida humana exigia antes de tudo um crescimento para o passado, uma espécie de enraizamento na tradição intelectual, em que o testemunho dos antepassados engrandecia, por sua autoridade, o transcurso do tempo. Gil Vicente, diz-nos ele no 
ensaio escrito sobre o autor em 1962, quando ainda estudante, "começa por um esboço e termina com uma diligente elaboração do problema" ${ }^{2}$ Cedia, neste momento, à tradição lusitana, não sem incorporar aquela preocupação com a participação judaica no exame da cultura brasileira. O terreno literário não era uma escolha aleatória nem significava uma fuga romântica e especulativa das realidades jurídicas que compunham o seu currículo acadêmico. Muito pelo contrário, era o esboço que lhe permitiria, anos mais tarde, elaborar diligentemente o papel do Direito no universo da política. A literatura, diz Celso Lafer no ensaio sobre Camões, escrito em 1964 para o Prêmio João Arruda que tive a honra de compartilhar com ele, "por efetuar-se no tempo, pode ao menos explicitar as diversas fases do processo cultural". 3

A companhia de Gil Vicente e de Camões deu a Celso, por assim dizer, os primeiros contatos com aquele humanismo autêntico que ousadamente não se sacrifica à primazia de uma verdade absoluta. A multiplicidade das verdades do homem do Renascimento, aliada à épica como a forma literária que abrange a totalidade da vida, de um lado. e, de outro. a percepção, no estudo vicentino, de que a literatura é marcada por sua época (embora nela também imprima a sua marca) e de que essa marca se transmite, por meio dela, a épocas futuras, traçaram, para Celso Lafer, o esboço de uma intelectualidade fortalecida que tanto o ajudaria, mais tarde, a confrontar-se com os problemas gerados por esta vida política atual, tão sem autoridade e sem a consciência de que a sua fonte transcende o poder e aqueles que o detêm.

A política é um tema antigo e permanente na reflexão de Celso Lafer. Quando, em 1965, foi para os Estados Unidos, iniciar seus estudos de pós-graduação na Universidade de Cornell, matriculou-se no curso de Hannah Arendt que já conhecia por seu livro "As origens do totalitarismo" O contrato com a extraordinária pensadora que marcaria tão profundamente os seus escritos, deslumbrou Celso Lafer, herói de sua história. Ao relembrar aquele tempo, na Introdução que escreveu ao ensaio "Hannah Arendt: pensamento, persuasão e poder" ${ }^{4}$ recorda-se ele ter suscitado, com ela, o debate sobre a relação entre arte e política e filosofia e política. Hannah Arendt, companhia fantástica que, desde então, jamais abandonou, ouvir com boa vontade suas preocupações intelectuais e os temas de seus estudos e investigações, tanto os mais próximos da órbita de interesses dela, como o Judeu em Gil Vicente, quanto os mais distantes, como os sobre as relações entre o planejamento e o sistema político brasileiro na presidência Kubitschek.

\footnotetext{
2 LAFER, Celso. Gil Vicente e Camões. São Paulo: Ática, 1978. p. 98.

3 LAFER, Celso. Gil Vicente a Camòes, cit.. p. 110.

- Id. Hannah Arendt: Pensamento, pursuasão c poder. Rio de Janeiro: Paz e Terra, 1979. p. 14.
} 
A companhia de Hannah Arendt significou, desde o princípio, a imponência de uma figura forte, mormente pela sua capacidade de reflexão abstrata a partir do dado concreto. Foi tão forte, como reconhece Celso, que alcançou até a dimensão do quotidiano. Numa tarde de inverno, relata ele, ${ }^{5}$ não se furtou a ponderarlhe, com tato, porém com firmeza, que o tamanho de sua barba - que tinha deixado crescer naquela época - não contribuía para a sua estética, o que o levou a apará-la, numa conviç̧ão antecipada de que ser e aparência coincidem, como iria aprender mais tarde na obra póstuma de Arendt: The Life of the Mind. Não se tome esta anedota, contudo, como um sinal de fraqueza e subserviência. Ao redigir o prefácio para a tradução brasileira de Entre o Passado e o Futuro, discutiu com ela, por carta, o texto elaborado, que foi objeto de alguma escaramuça interpretativa entre ambos, reagindo Celso, epistolamnente, em pontos que entendia seu dever reafirmar. ${ }^{6}$ Era como se ele, naquele momento, fosse ao encontro do velho adágio romano "amicus Sócrates, amicus Plato - amicus Arendt -, sed magis aestimanda veritas" Não se tratava, porém, de uma sobreposição imponente da verdade, retoricamente absoluta, como não se tratava antes de uma subserviência medíocre. Afirmava-se para Celso Lafer, naquele instante, o sentido da liberdade, base da reflexão sobre o poder, decisiva na ciência como nas artes, na filosofia como na vida.

O tema da liberdade, cuja importância ele ressaltou nas condições da racionalidade da decisão administrativa no planejamento governamental brasileiro no período Kubitschek e no estudo do pensamento de Octavio Paz, para quem a sobrevivência da política está ligada ao esforço de conversão da sociedade em poesia, pelo exercício criativo da liberdade Kubitschek e Octavio Paz, duas outras extraordinárias companhias de Celso Lafer é o ponto de convergência e de concomitância indissolúvel entre razão e existência. Em contraste com uma filosofia do homem, que parte do diálogo solitário do eu consigo mesmo, Celso Lafer parte decididamente para uma filosofia da humanidade, que pressupõe o diálogo com os outros. Em todos os seus trabalhos, ele nunca está só. Costura com incomparável perícia e erudição uma teia de argumentos proporcionados pelas leituras e experiências que acumulou de forma invejável. Como poucos sabe ele conjugar a informação com o saber. Aqui Max Weber, ali Raymond Aron, neste ponto Miguel Reale, naquele Goffredo Silva Telles, num momento Gian Baptista Viço, num outro Emmanuel Kant, às vezes Maquiavel e Hobbes, outras Rousseau e Stuart Mill. Pois deste intrincado de idéias, que tem para ele são suas as palavras ${ }^{7}$ algo de devoração crítica à maneira de Oswald de

LAFER, Celso. Hannah Arendt: Pensamento. persuasão e poder. cit., p.16.

6 Id. ibid., p. 17. 
Andrade, surge, numa forma academicamente disciplinada e bem comportada. um diálogo fecundo que ele transforma em perspectivas de análise e síntese de orientação.

A liberdade está para Celso Lafer no centro de suas preocupações. Em sua tese de titularidade cita ele o poeta grego Arquíloco para sugerir uma compreensão do traço definidor de Hannah Arendt. ${ }^{8}$ Dizia Arquíloco: "Muitas coisas sabe a raposa; mas o ouriço uma grande." Se olharmos o conjunto de suas reflexões e a diversidade de pontos de vista de que se apropria com maestria e elegância, Celso Lafer é, sem dúvida, uma raposa. Mas, diria eu, uma raposa ouriçada, que tem na liberdade o vetor decisivo de sua percepção da realidade. Outra, aliás, não poderia ter sido sua opção. Filho de uma geração acadêmica educada para o exercício cívico da cidadania sob a tutela da Constituição de 1946, sentiu, como todos os seus colegas, o duro golpe de uma revolução que substituiu a legitimidade do voto pela coerção organizada, que no lugar do consenso formado pelo embate dialógico das opiniões impôs o monólogo de uma suposta eficiência tecnocrática, que substituiu o papel participante da sociedade civil pela apatia das razões supremas da segurança nacional, que transformou o espaço público da palavra num jogo de silenciosas conivências. Em 1975, ao fazer um balanço do Sistema Político brasileiro pós-64, Celso Lafer era, por isso, capaz de ver, por entre as brumas de seus resultados econômicos, os traços distintos dos custos da revolução: custos políticos em termos de supressão de liberdades públicas; custos sociais em termos de acentuadas desigualdades na distribuição de renda; custos culturais em termos de um amortecimento da criatividade. ${ }^{9}$ Diante do inexorável dessa percepção dos fatos, ele era capaz, no entanto, de sentir, em suas próprias palavras, que "o campo do possível e, no caso, do desejável, é sempre maior e mais amplo do que aquilo que acaba se consubstanciando em realidade" ${ }^{10}$ Daí o seu empenho em contribuir para a constitutio libertatis entre nós, para o espaço público da palavra viva e da ação livre, que ele afirma, com Hannah Arendt, estar "na raiz da verdadeira inspiração revolucionária do mundo moderno" "I

Liberdade não é aqui apenas o sopro de uma voz. Ela está existencialmente presente em sua busca da modernidade brasileira, na qual o desempenho econômico e a democracia política devem mesclar-se de maneira superior.

Dela faz parte constitutiva, no dizer de Tocqueville, outra de suas companhias, "a preocupação salutar com o futuro, que faz vigiar e combater" Não sendo

LAFER, Celso. A reconstrução dos Direitos Humanos: um diálogo com o pensamento de Hannah Arendt. São Paulo: Cia da Letras, 1988. p. 20.

s Id. Ibid., p. 13.

9 LAFER, Celso. O sistema politico brasileiro. São Paulo: Perspectiva. 1984. p. 20.

10 Id. Ibid.. p. 14.

1 Id. Ibid., p. 15. 
propriamente um princípio, mas um início, dada a natureza temporal e contingente do homem, a liberdade está no cerne de sua extraordinária tese sobre a Reconstrução dos Direitos Humanos que vê no enraizamento concreto da cidadania o direito de ter direitos, posto que a igualdade, não sendo um dado, há de ser um construído da convivência no espaço público. É isto que faz da liberdade possibilidade de iniciar coisas novas, não solitariamente, mas em concurso com os outros, e faz da coexistência política, memória organizada que se transmite por tradição.

Celso Lafer, contudo, está longe de ser um idealista crédulo. Ao contrário, está consciente desta brutalização do homem pelo homem que ele enxerga agudamente, como scholar do Direito Internacional que é, no absurdo da guerra nuclear, na irracionalidade do terrorismo, mas sobretudo na condenação de grandes massas à miséria e à fome, num mundo que, paradoxalmente, vê o poder crescer pela multiplicação dos meios de atuação e pela extensão dos meios de controle sobre a sociedade. Como enfrentar esse mundo, marcado pela contradição de interesses polares e pela angústia dos becos sem saída?

Existe, nessa questão, uma arquitetura dramática, cuja personificação mais profunda está no jogo labiríntico do poder. Celso Lafer aprendeu desde cedo, com seu mestre Miguel Reale, que estão destinadas ao insucesso todas as doutrinas que procuram eliminar do Direito o conceito de poder. Mas o poder, percebeu ele desde logo, é uma hidra de muitas cabeças. Tem algo daquela relação assimétrica em que a pura força impõe submissão. No entanto, poder não é violência. Aparece também nas relações voluntárias de acatamento e respeito. Contudo, poder não se confunde com autoridade. A violência dos cidadãos, quando dela fazem uso para desmascarar seus governantes, ou a violência destes, para se manterem no governo, são manifestações petrificadas e decadentes do poder. Mas a autoridade ensimesmada, que desconhece o consenso e parte da premissa sublimadora de uma verdade universal, age num vácuo e emascula o poder. É, porém, nesse hiato entre a superficie da força e o abismo da autoridade que o poder é gerado. Nem violência de alguns contra todos, ou de todos contra alguns, nem autoridade de alguém ou de poucos sobre muitos, poder é para ele um fenômeno plural, um agir conjunto cuja marca manifesta é a formação de uma vontade comum. Não exige subserviência, mas apoio. Não prescinde de acatamento e respeito, mas se funda na capacidade dos membros de uma comunidade política de concordarem com um curso comum de ação.

Celso Lafer, herói de sua própria história, é um homem perspicaz. Sabe por isso onde encontrar o poder, mas sabe também com quantas máscaras por traz dele 
se escondem a violência da força e a sublimação da ideologia. Por isso desconfia com argúcia de idéias radicais, como as que florescem nos tempos de crise, e que acreditam mudar o rumo das coisas pela captura de sensatez e pela demagogia da imaginação. Prefere, como disse recentemente, descobrir as brechas e aproveitar as oportunidades. A realidade, porém, pode ser pensada com clareza e distinção. Mas não é clara nem distinta por ela mesma. Isto coloca para Celso Lafer uma questão que vai aos limites do existencial: o fato de que a vida humana. embora condicionada pela necessidade da sobrevivência, pelo mundo do trabalho e do agir conjunto, não tem nessas condições reais algo de absoluto, força o homem a perquirir além de suas próprias condicionalidades. Daí o sentido dramático e fundamente enraizado de sua reflexão sobre o poder: como livrar-se do embotamento crítico em que o nosso julgamento é atirado por um mundo consumista, em que tudo é perecível e supérfluo, em que só se avalia o homem, os artefatos humanos e a própria natureza em termos de desempenhos e resultados?

Celso Lafer é um homem tenaz e paciente, que cultiva a prudência e a tolerância como virtudes gravitacionais do jurista. Não é sem razão que o direito foi por ele escolhido, desde cedo, como o lugar privilegiado do seu estudo, da sua vida profissional e da sua vocação docente. E é no direito que Celso Lafer busca respostas às suas próprias inquietações. Trata-se de uma perspectiva universal que lhe permite aderir aos valores permanentes em que acredita sem desconsiderar o tempo e o espaço em que atua. Afinal, como diz ele mesmo, lembrando Ortega y Gasset, a perspectiva é um dos componentes da realidade e, por isso mesmo, longe de ser uma deformação da realidade, constitui a forma específica de sua organização.

Com Norberto Bobbio, uma de suas companhias mais constantes, ${ }^{12}$ Celso Lafer observa que para os juristas que partem do Direito Privado, o direito tende a ser visto como um conjunto de relações intersubjetivas, caracterizadas por um vínculo de obrigatoriedade de normas que estabelecem competências. Sua própria experiência profissional, concentrada, de um lado no Direito Empresarial e de outro, no Direito Internacional Público e nas Relações Internacionais, fê-lo ver uma certa convergência naquelas perspectivas. Afinal, o direito é sempre um dado, algo que já está, desde sempre, presente nas articulações humanas quando delas participamos. Mas que pode ser usado e reelaborado pelos atores sociais. Por isso ele é vínculo e instrumento. Dá o contorno social, mas pode também alterá-lo. Tem, ao mesmo tempo, o sentido de

LAFER, Celso. O Brasil e a crise mundial. São Paulo: Perspectiva, 1984. p. 20. 
estabilidade e da mudança. Não sobrepaira ao jogo da vida, mas é constituído dentro dele. Nesse sentido, repousa no consenso geral da comunidade. ${ }^{13}$

Deste modo, o direito, não apenas como limite e fronteira do espaço humano, mas como princípio de sua ação, é para Celso Lafer uma ilha de certeza num oceano de incertezas. Como não se trata, porém, de uma certeza permanente, é preciso lutar por ele. "É preciso que lute o povo pela lei, tal como pelas muralhas", lembra ele, citando um famoso fragmento de Heráclito. ${ }^{14} \mathrm{O}$ que vale, aliás, sobretudo para um mundo em que a erosão dos vínculos políticos faz o direito perder, para o homem comum, sua identidade e sua confiabilidade.

Lutar pelo direito é para Celso Lafer lutar contra a sua perversão funcional que dele faz apenas forma para um conteúdo discricionário. Olhar o poder da perspectiva do direito, diz ele, obriga à pergunta: para que serve o direito? Mas a resposta não deve deixar-se envolver pelo clima utilitarista e consumista de uma sociedade voltada para a sobrevivência como seu único valor. Afinal, como se diria com Hobbes, o homem para o qual resta apenas sua própria sobrevivência, não conhece outro comportamento senão a luta selvagem de todos contra todos. E Celso Lafer sabe, como poucos, quão desfavorável tem sido para o Brasil a verdadeira impunidade jurídica e política da administração pública, acostumada a tomar suas decisões em nome de supostas razões técnicas, que excluem a participação da cidadania e acabam por fomentar um regime de favores e desmandos. Sabe também de uma crise social, fundada numa crise econômica de enorme dimensão, que exige um mínimo de solidariedade e civismo, mas que acaba sendo um vértice de desconfianças. Sabe sobretudo da pressão pungente da miséria de uma imensa massa de alienados da cidadania, que vive à margem do País formal. "Éramos vistos, resume ele numa entrevista recente, como o país dos sonhos e das esperanças e agora somos encarados como o pais dos pesadelos e das ineficiências"

Pois é justamente a percepção dessa realidade que faz de Celso Lafer um filósofo crítico, no exercício de sua docência jurídica, e um empresário politicamente consciente na sua vida pública. É preciso denunciar, em todos os lugares, a qualquer tempo e em todas as circunstâncias, na política como na vida privada, na cátedra como nos tribunais, nas relações internas como nas internacionais, que, se no mundo moderno, cabe ao direito positivo encaminhar de modo controlado o processo decisório no Estado e na Sociedade, cabe ao jurista a vigilância permanente para que se garanta ao cidadão o acesso ao espaço público; ao ser humano, sua pluralidade e diversidade; à vida política, o sentido do agir conjunto, e à sociedade, a tutela contra a desolação da miséria.

13. LAFER, Celso. A reconstrução dos Direitos Humanos, cit., p. 255.

is LAFER, Celso. op. cit., p. 219. 
Eis aí, meus amigos, Celso Lafer, a quem recebemos hoje, solenemente, como professor titular desta Faculdade. Senso hislórico, saber jurídico e político, reflexão filosófica fazem dele um mestre que, como ele próprio disse certa vez de Antônio Cândido, companhia inseparável de tantos anos, "pelo exemplo de sua obra e com o encanto de sua figura humana"" há de ser para a mocidade desta Academia um guia intelectual e um paradigma de homem público.

São Paulo, dezembro, 2006.

LAFER, Celso. Gil Vicente e Camôes, cit., p. 12. 


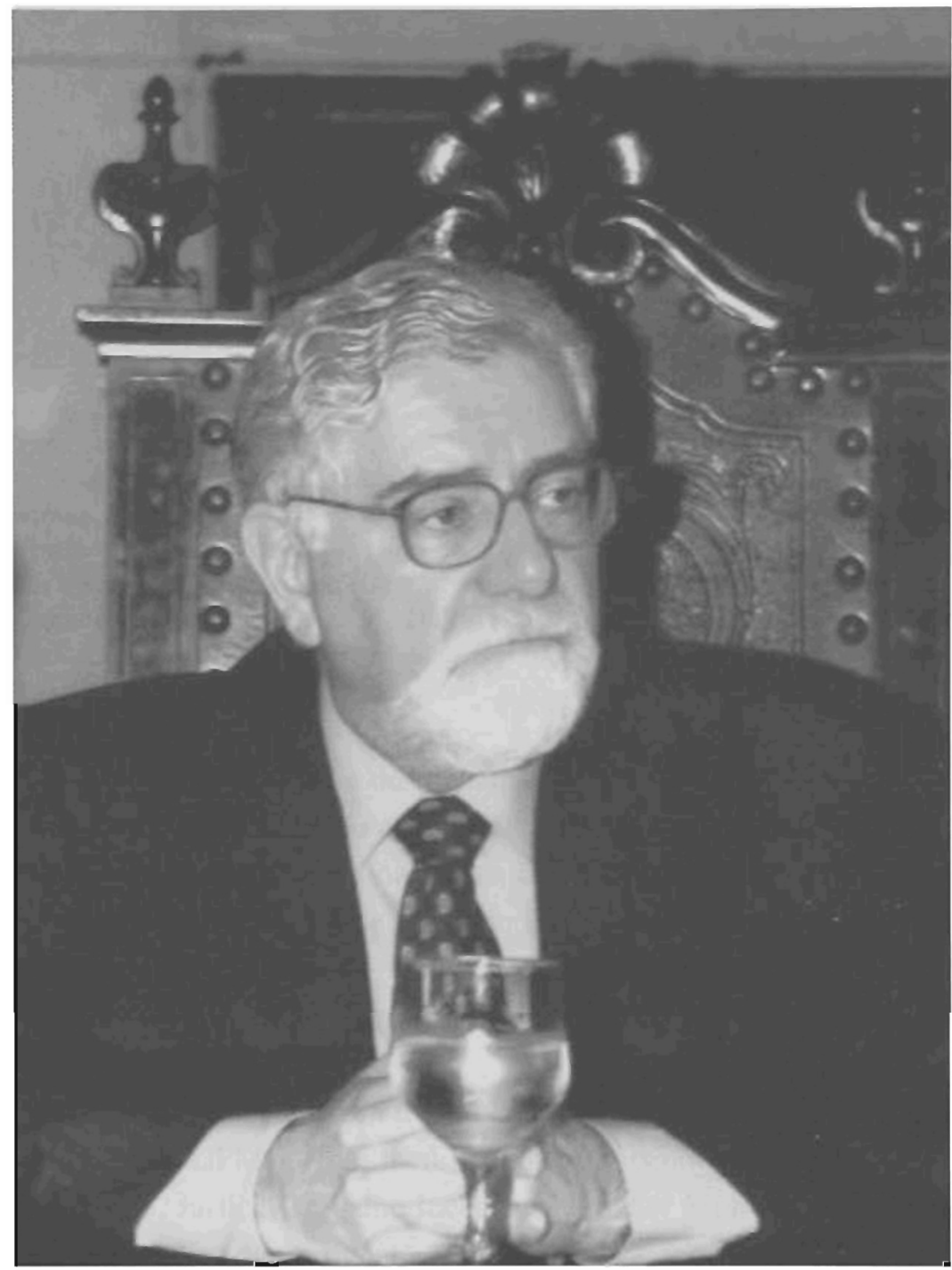

\section{Professor Titular Celso Lafer}

